\title{
NANOFILME ANTIRREFLEXIVO DE SÍLICA CONFECCIONADO PELO PROCESSO SOL-GEL PARA APLICAÇÃO SOLAR*
}

Débora Guimarães da Silva' Vilma Conceição Costa² Rogério Antônio Xavier Nunes ${ }^{3}$

\section{Resumo}

Este trabalho trata da deposição de um nanofilme de sílica através do processo solgel na superfície de um substrato vítreo para sua aplicação em usinas térmicas de energia solar. Os filmes foram confeccionados pelo processo de revestimento por imersão utilizando-se um equipamento dip-coating e passaram por um tratamento térmico à $425^{\circ} \mathrm{C}$ durante 30 minutos. Na etapa de caracterização foram feitos ensaios de espectroscopia de fluorescência de raios-X, refletância difusa no UV-Vis, microscopia eletrônica de varredura e medidas de molhabilidade. As propriedades mecânicas foram avaliadas por teste de adesão da fita e dureza a lápis. Resultados dos ensaios de espectroscopia de fluorescência de raios-X confirmaram haver a deposição de sílica sobre o substrato. Foi obtida uma refletância difusa de 2,72\% para o filme antirreflexivo. Imagens no MEV revelaram uma superfície lisa, uniforme $\mathrm{e}$ isenta de trincas. Medidas de molhabilidade mostraram que houve o molhamento dos filmes pela água, caracterizando-os como hidrofílicos. Os filmes apresentaram uma adesão de 4B e dureza de $3 \mathrm{H}$. Os nanofilmes de sílica confeccionados apresentaram propriedades ópticas e mecânicas satisfatórias para a aplicação solar.

Palavras-chave: Nanofilme de sílica; Revestimento antirreflexivo; Processo sol-gel; Energia solar.

\section{ANTIREFLECTIVE SILICA NANOFILMS PRODUCED BY THE SOL-GEL PROCESS FOR SOLAR APPLICATION}

\section{Abstract}

This paper deals with the deposition of silica nanofilms by the sol-gel process in a glass substrate for its application in solar power plants. The films were prepared by dip-coating process and heat-treated at $425^{\circ} \mathrm{C}$ for 30 minutes. The characterization was performed by X-ray fluorescence spectroscopy, scanning electron microscopy and wettability measurements. Mechanical properties were evaluated by adhesion tape test and pencil hardness. X-ray fluorescence spectroscopy has confirmed the silica deposition on the substrate. A diffuse reflectance of $2.72 \%$ was obtained to the antireflective films. Images in SEM revealed a smooth surface, free from cracks. The wettability measurements showed that, for all films, there was wetting of the film by water, characterizing them as hydrophilic. The films' adhesion was 4B and its hardness was $3 \mathrm{H}$. The silica nanofilms showed good optical and mechanical properties for its application in solar area.

Keywords: Silica nanofilm; Antireflective coating; Sol-gel process; Solar energy.

Engenharia de Materiais, Mestre, CEFET/MG, Belo Horizonte, Minas Gerais, Brasil.

2 Engenharia de Materiais, Doutora, Pesquisa, Polícia Civil de Minas Gerais, Belo Horizonte, Minas Gerais, Brasil.

3 Engenharia de Materiais, Doutor, Docente, POSMAT, CEFET/MG, Belo Horizonte, Minas Gerais, Brasil. 


\section{INTRODUÇÃO}

A utilização de revestimentos antirreflexivos tem atraído a atenção da comunidade tecnológica e científica graças a possibilidade de se melhorar as propriedades óticas de diferentes materiais para as mais variadas aplicações, tais como painéis solares, coletores solares, telas de dispositivos de vídeo, óculos, janelas, etc. ${ }^{1-4}$.

$\mathrm{Na}$ geração de eletricidade através da energia do sol, quer seja em sistemas térmicos de energia solar ou fotovoltaicos, os revestimentos antirreflexivos desempenham um importante papel reduzindo perdas por reflexão da luz. Cálculos mostram que a energia produzida anualmente por uma usina termossolar, onde a temperatura do fluido do coletor solar é $100^{\circ} \mathrm{C}$, pode ser aumentada em até $20 \%$ através da aplicação de uma camada antirreflexiva na cobertura vítrea ${ }^{5}$.

Diferentes processos e materiais vêm sendo estudados na obtenção de superfícies antirreflexivas, sendo o óxido de silício $\left(\mathrm{SiO}_{2}\right)$ obtido mediante o emprego do processo sol-gel aquele que apresenta melhores resultados de refletância ${ }^{1-5}$. $O$ processo sol-gel trata-se de uma rota de síntese onde, através do estabelecimento de ligações entre as partículas coloidais ou cadeias poliméricas há a formação de uma rede sólida tridimensional, havendo a transição do sistema sol para um sistema gel $^{6}$. Em geral, a síntese de partículas de $\mathrm{SiO}_{2}$ pelo processo sol-gel é feita através da hidrólise e condensação de alcoxi-silanos tais como tetrametilortosilicato (TMOS) ou tetraetilortosilicato (TEOS), com a adição de água, álcool e um catalisador ácido ou básico ${ }^{2,7-8}$.

Uma importante peculiaridade do processo sol-gel é que antes da gelificação do sol ele é ideal para a preparação de filmes finos. Sendo que através dele é possível se obter um controle preciso sobre a microestrutura do filme formado, como a área de superficial, volume e tamanho dos poros ${ }^{1,6,9}$. A estrutura porosa formada durante a confecção do filme faz com que os filmes de sílica obtidos pelo processo sol-gel apresentem uma baixa refletância. Isso porque ela reduz o índice de refração da camada até valores suficientemente baixos, permitindo chegar à reflexão zero da luz pela superfície em um único comprimento de onda ${ }^{1-2,4-5}$.

Atualmente diferentes técnicas são empregadas na confecção da camada antirreflexiva, em conjunto com o método sol-gel, como a técnica dip-coating, sputtering e spin-coating. Sendo a técnica do dip-coating é a mais indicada e empregada na produção de camadas antirreflexivas, especialmente quando se necessita do recobrimento de grandes áreas e materiais com formas complexas, com a vantagem de um baixo custo de implantação e operação em comparação às demais técnicas ${ }^{2,4-7.10}$.

Este trabalho teve como objetivo promover a deposição, através do método sol-gel, de uma fina camada de revestimento antirreflexivo constituído de sílica porosa sobre a superfície de um substrato vítreo visando aumentar sua transmissividade à radiação solar em decorrência da redução em perdas por reflexão do vidro. Foram observados os efeitos do tratamento térmico e velocidade de deposição do filme no dip-coating na refletância das amostras. 


\section{MATERIAIS E MÉTODOS}

\subsection{Preparação do sol de sílica e confecção do revestimento antirreflexivo}

O sol de sílica foi preparado através da mistura de tetraetilortossilicato (TEOS), água deionizada e álcool etílico. Ácido clorídrico foi utilizado como catalisador para a obtenção de condições ácidas.

Os filmes foram confeccionados através do processo de revestimento por imersão utilizando-se um equipamento dip-coating, sendo utilizadas lâminas de vidro de microscópio como substrato. As velocidades imersão e retirada adotadas foram de 2, 4, 6, 8, 10 e $12 \mathrm{~cm} / \mathrm{min}$. Em seguida eles passaram por um tratamento térmico à temperatura de $425^{\circ} \mathrm{C}$ durante 30 minutos.

\subsection{Caracterização do revestimento antirreflexivo}

As amostras foram caracterizadas através dos espectros de refletância difusa na região do ultravioleta-visível (UV-2600 Plus - Shimadzu) dentro do intervalo de comprimentos de onda de 200 a $1400 \mathrm{~nm}$. Para o cálculo da refletância média das amostras adotou-se o teorema do valor médio para a integral da curva de refletância (Equação 1) no intervalo de comprimentos de onda de maior intensidade de irradiação solar, 350 a $900 \mathrm{~nm}^{11}$. Onde $R_{\text {méd }}$ é a refletância média no intervalo de comprimento de onda analisado; $\lambda_{i}$ e $\lambda_{f}$ são respectivamente os comprimento de onda inicial e final do intervalo analisado e $R$ é a refletância medida para cada comprimento de onda.

$$
R_{m e ́ d}=\frac{1}{\lambda_{f}-\lambda_{i}} \int_{\lambda_{i}}^{\lambda_{f}} R(\lambda) d \lambda
$$

Com base nos resultados de refletância foi calculado o índice de refração de cada amostra para os comprimentos de onda onde ocorre o mínimo de reflexão, conforme Equação 2. Assumindo que o índice de refração do ar seja igual a 1,04,12. Onde $R_{\text {min }}$ é a refletância mínima obtida para o filme, $n_{\min }$ é o índice de refração do filme e $n_{a r} 0$ índice de refração do ar.

$$
\boldsymbol{R}_{\min }=\left(\frac{n_{\text {filme }}^{2}-\left(n_{\text {ar }} n_{\text {filme }}\right)}{n_{\text {filme }}^{2}\left(n_{\text {ar }} n_{\text {filme }}\right)}\right)^{2}
$$

A partir dos valores de índice de refração foi possível calcular a transmitância máxima de cada amostra (Equação 3), que é a transmitância correspondente ao comprimento de onda onde ocorre o mínimo de reflexão ${ }^{13}$. Onde $T_{\text {máx é a }}$ transmitância máxima do filme.

$$
T_{\text {máx }}=\frac{4 n_{\text {ar }} n_{\text {filme }}}{\left(n_{\text {ar }}+n_{\text {filme }}\right)^{2}}
$$

Através dos valores de índice de refração também foi calculada a porosidade das amostras. Considerando que o índice de refração do filme é composto por uma fração referente ao índice de refração do ar nos poros do filme, e por outra fração referente ao índice de refração da sílica densa. A porosidade dos filmes pôde ser calculada através da Equação 4, assumindo que o índice de refração da sílica densa seja igual a $1,46^{14}$. Onde $P$ é a porosidade do filme e $n_{S i}$ é o índice de refração da sílica densa.

$$
n_{\text {filme }}=n_{a r} P+n_{S i}(1-P)
$$


Foi feita microscopia eletrônica de varredura (Superscan SSX-550 - Shimadzu) sendo as imagens obtidas por detecção de elétrons secundários. A varredura ao longo das amostras foi conduzida com aumento de 100X. Foram realizados ensaios de molhabilidade com as medidas de ângulo de contato feitas utilizando um tensiômetro. A realização dos ensaios teve como base a técnica da gota séssil (sessile drop) para medição do ângulo de contato de avanço, conforme descrito na norma ASTM D7334-08 ${ }^{15}$.

A espectroscopia de fluorescência de raios-X com energia dispersiva (EDX-720 Shimadzu) foi empregada como método semi-quantitativo na detecção dos elementos químicos presentes no substrato vítreo e no filme de sílica. $O$ resultado obtido foi expresso em quantidade percentual em massa dos elementos químicos presentes nas amostras.

A aderência entre o filme e o substrato foi avaliada pelo teste de aderência pelo método de corte cruzado descrito na norma ASTM D3359-09 ${ }^{16}$. Sendo a aderência do filme avaliada de forma visual comparando a quantidade de revestimento desprendida com uma escala de adesão estabelecida pela norma.

A dureza do filme de sílica foi medida através do ensaio de dureza a lápis de acordo com a norma ASTM D3363-05 ${ }^{17}$. Para a realização do ensaio foi utilizado um aparelho para teste de dureza a lápis Wolff-Wilborn modelo Europeu, que baseia-se em 14 níveis de durezas diferentes de lápis (de 6B a $6 \mathrm{H}$ ). $\mathrm{O}$ ensaio iniciou-se pelo lápis mais duro, seguindo a escala até o lápis onde se obteve a marca do grafite do lápis no filme. A dureza do filme foi dada pelo lápis de menor dureza que não deixou marca de grafite no filme.

\section{RESULTADOS E DISCUSSÃO}

\subsection{Espectroscopia na região do ultravioleta-visível}

Na Figura 1 são apresentados os espectros de refletância difusa na região do ultravioleta-visível do substrato vítreo e dos filmes antirreflexivos após o tratamento térmico. Ao se avaliar os espectros de refletância difusa da Figura 1 nota-se que os filmes apresentaram refletância inferior à do substrato limpo em praticamente todos os valores de comprimentos de onda. Levando em consideração apenas a faixa de comprimento de onda com maior intensidade energética de irradiação solar ${ }^{11}$ (350 a $900 \mathrm{~nm}$ ) a amostra que obteve menor valor de refletância, em um único comprimento de onda, foi a amostra com velocidade de deposição de $4 \mathrm{~cm} / \mathrm{min}$, com valor mínimo de refletância de 2,25\% em $889 \mathrm{~nm}$. 


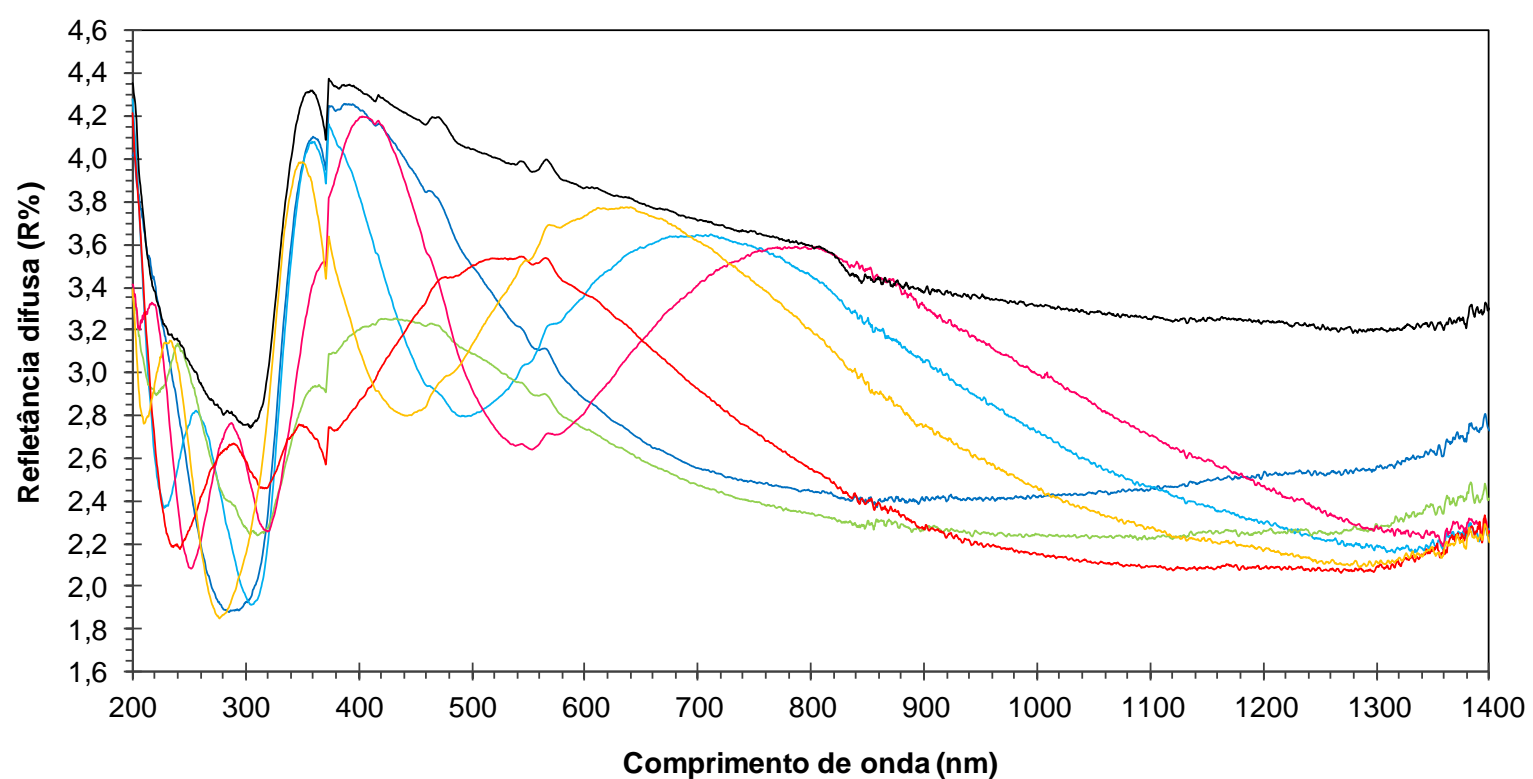

- Filme antirreflexivo, velocidade de deposição de $2 \mathrm{~cm} / \mathrm{min}$

_ Filme antirreflexivo, velocidade de deposição de $10 \mathrm{~cm} / \mathrm{min}$

_ Filme antirreflexivo, velocidade de deposição de $4 \mathrm{~cm} / \mathrm{min}$

— Filme antirreflexivo, velocidade de deposição de $12 \mathrm{~cm} / \mathrm{min}$

— Filme antirreflexivo, velocidade de deposição de $6 \mathrm{~cm} / \mathrm{min}$

_ Substrato vítreo limpo

- Filme antirreflexivo, velocidade de deposição de $8 \mathrm{~cm} / \mathrm{min}$

Figura 1. Espectro de refletância difusa na região do ultravioleta-visível (UV-Vis) do substrato vítreo e das amostras com filme antirreflexivo.

$\mathrm{Na}$ Tabela 1 são apresentados os resultados de índice de refração, transmitância máxima e porosidade dos filmes antirreflexivos. Os valores de índice de refração e transmitância variam de acordo com o valor de comprimento de onda ${ }^{18}$, e os valores apresentados na Tabela 1 são correspondentes apenas ao comprimento de onda correspondente à reflexão mínima $\left(\lambda_{\min }\right)$ de cada amostra. Verifica-se que dentre todas as amostras o menor valor de índice de refração alcançado foi igual a 1,41. Embora esteja acima do índice de refração ideal $(n=1,22)$, o valor encontrado está dentro do esperado de acordo com trabalhos que utilizam rota de síntese parâmetros de confecção similares ${ }^{9}$.

Tabela 1. Índice de refração, transmitância máxima e porosidade dos filmes antirreflexivos

\begin{tabular}{lccccc}
$\begin{array}{c}\text { Velocidade de } \\
\text { deposição }\end{array}$ & $\mathbf{R}_{\text {min }}(\%)$ & $\boldsymbol{\lambda}_{\min }(\mathbf{n m})$ & $\mathbf{n}_{\text {filme }}$ & $\mathbf{T}_{\text {máx }}$ & Porosidade \\
\hline $02 \mathrm{~cm} / \mathrm{min}$ & 1,8791 & 285,50 & 1,4118 & $97,09 \%$ & $10 \%$ \\
\hline $04 \mathrm{~cm} / \mathrm{min}$ & 2,2172 & 1089,00 & 1,4295 & $96,88 \%$ & $7 \%$ \\
\hline $06 \mathrm{~cm} / \mathrm{min}$ & 2,0623 & 1269,00 & 1,4215 & $96,97 \%$ & $8 \%$ \\
\hline $08 \mathrm{~cm} / \mathrm{min}$ & 1,8490 & 277,00 & 1,4101 & $97,11 \%$ & $11 \%$ \\
\hline $10 \mathrm{~cm} / \mathrm{min}$ & 1,9131 & 305,00 & 1,4136 & $97,07 \%$ & $10 \%$ \\
\hline $12 \mathrm{~cm} / \mathrm{min}$ & 2,0828 & 252,00 & 1,4226 & $96,96 \%$ & $8 \%$ \\
\hline
\end{tabular}

Em relação ao percentual de poros verifica-se que todas as amostras apresentaram um baixo valor de porosidade, inferior a $11 \%$. Este resultado era esperado, uma vez que, ao se utilizar um catalisador ácido na síntese o crescimento do sol de sílica 
tende a formar cadeias lineares que se sobrepõem dando origem a um filme compacto com porosidade de aproximadamente $10 \%{ }^{4,14}$.

Todas as amostras apresentaram transmitância máxima superior a 96\%. O valor de transmitância pontual não é relevante, uma vez que para aplicação solar os filmes devem exibir uma elevada transmitância dentro de uma faixa de comprimento de ondas e não em um único ponto. No entanto, ele serve como um comparativo com trabalhos similares que também utilizam revestimento de sílica na obtenção do antirreflexo, e que apresentam seus resultados em termos de transmitância pontual. Comparando com resultados de outros trabalhos o valor de transmitância máxima encontrado para os filmes de sílica está de acordo com o esperado ${ }^{19-20}$.

$\mathrm{Na}$ Figura 2 são apresentados os resultados de refletância difusa média, no intervalo de comprimento de ondas de maior intensidade de irradiação solar ${ }^{11}$ (350 a $900 \mathrm{~nm}$ ), para o substrato vítreo e para os filmes antirreflexivos. Todos os filmes de sílica apresentaram refletância difusa média inferior à do revestimento antirreflexivo $(3,86 \%)$. O menor valor refletância difusa $(2,72 \%)$ foi obtido para o filme confeccionado com velocidade de deposição de $4 \mathrm{~cm} / \mathrm{min}$.

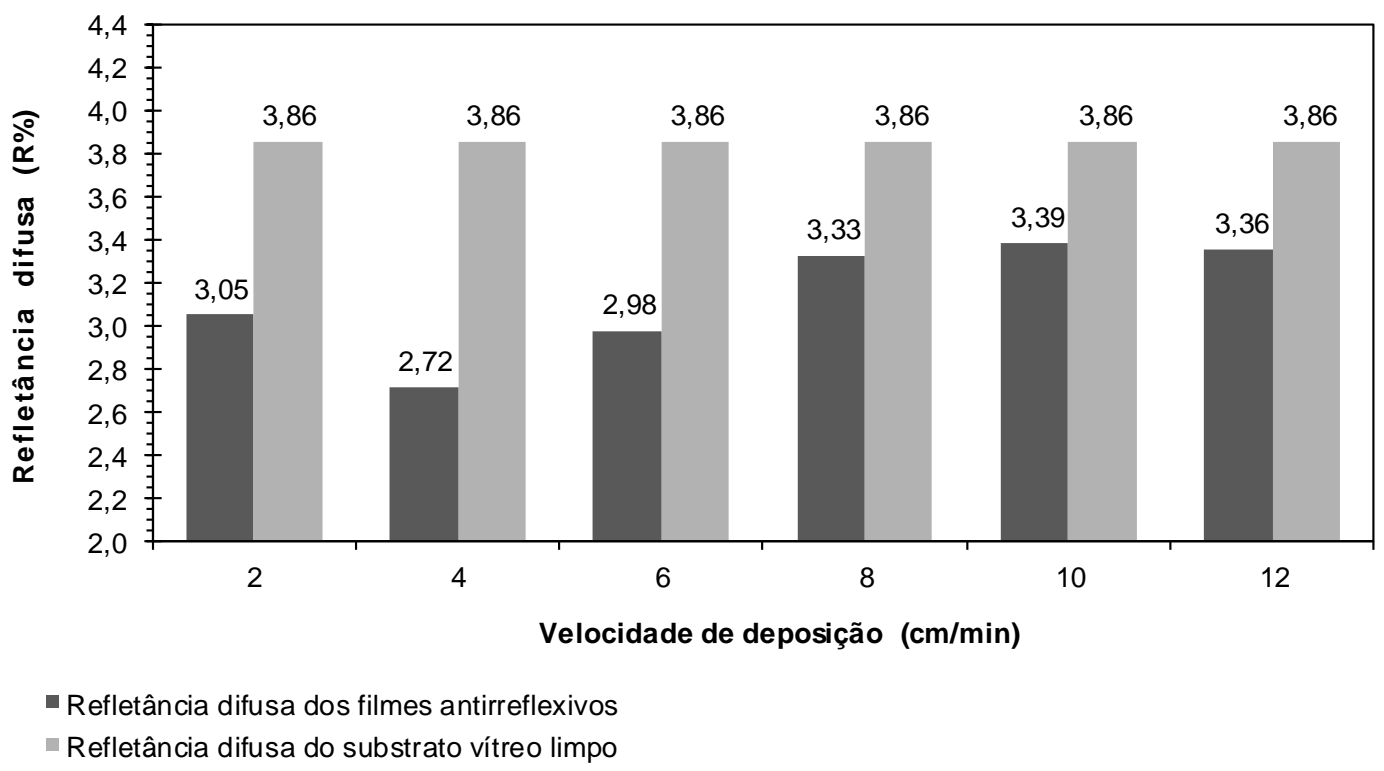

Figura 2. Refletância difusa média do substrato vítreo limpo e dos filmes antirreflexivos no intervalo de comprimento de ondas de 350 a $900 \mathrm{~nm}$.

\subsection{Microscopia eletrônica de varredura}

Na Figura 3 são apresentadas as imagens obtidas por microscopia eletrônica de varredura, dos filmes antirreflexivos com aumento de aumento de 100X na região central das amostras. É possível observar, dentro dos limites de ampliação permitida pelo equipamento, que todos os filmes apresentam homogeneidade e ausência de trincas. Não foram observadas mudanças nítidas na superfície dos filmes com a variação da velocidade de deposição do filme. 


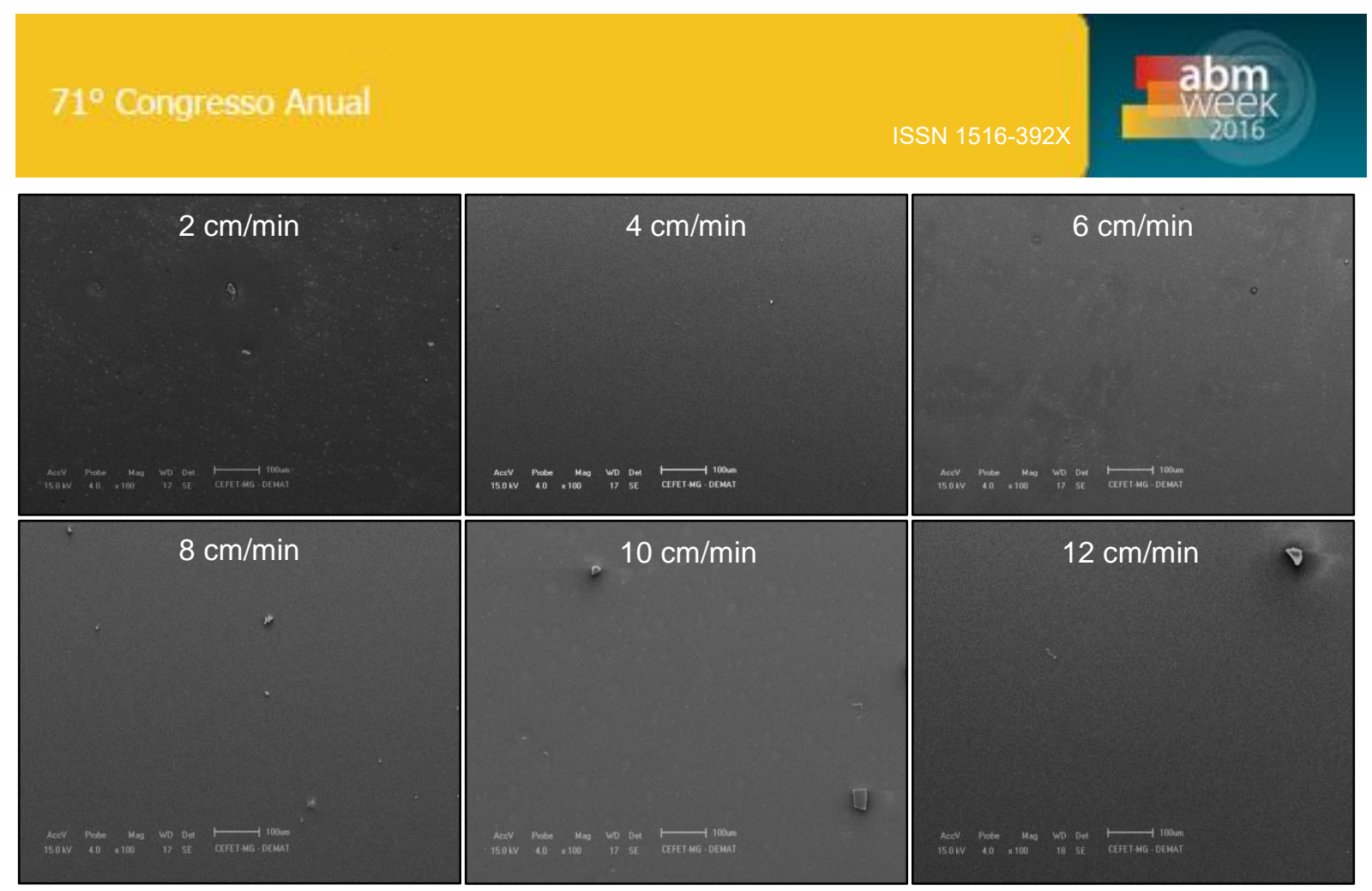

Figura 3. Imagens obtidas por microscopia eletrônica de varredura dos filmes antirreflexivos com aumento de 100X na região central das amostras.

\subsection{Espectroscopia de fluorescência de raios- $X$ com energia dispersiva}

Os resultados obtidos por espectroscopia de fluorescência de raios-X do substrato vítreo e dos filmes de sílica são apresentados na Tabela 2. Avaliando os resultados nota-se que para todas as amostras o percentual de sílica aumentou em comparação com o substrato vítreo comprovando haver deposição de sílica sobre o substrato. Os demais elementos químicos detectados no ensaio são referentes à composição química do substrato.

Verifica-se que o aumento na velocidade de deposição dos filmes resultou em um aumento no percentual de sílica das amostras. Este resultado comprova que é possível aumentar na espessura dos filmes mediante um aumento na velocidade de deposição dos filmes no dip-coating. Tal resultado condiz com o proposto em teoria, e verificado experimentalmente por outros autores ${ }^{1-2,6}$.

Tabela 2. Composição química por espectroscopia de fluorescência de raios-X para o substrato vítreo e para filmes antirreflexivos de sílica

\begin{tabular}{|c|c|c|c|c|c|c|c|}
\hline \multirow{2}{*}{$\begin{array}{l}\text { Elemento } \\
\text { químico }\end{array}$} & \multirow{2}{*}{$\begin{array}{l}\text { Substrato } \\
\text { vítreo }\end{array}$} & \multicolumn{6}{|c|}{ Filmes antirreflexivos de sílica } \\
\hline & & $2 \mathrm{~cm} / \mathrm{min}$ & $4 \mathrm{~cm} / \mathrm{min}$ & $6 \mathrm{~cm} / \mathrm{min}$ & $8 \mathrm{~cm} / \mathrm{min}$ & $10 \mathrm{~cm} / \mathrm{min}$ & $12 \mathrm{~cm} / \mathrm{min}$ \\
\hline Silício & $70,216 \%$ & $70,646 \%$ & $71,017 \%$ & $71,408 \%$ & $71,431 \%$ & $71,785 \%$ & $71,936 \%$ \\
\hline Cálcio & $23,946 \%$ & $23,032 \%$ & $23,301 \%$ & $23,028 \%$ & $23,008 \%$ & $22,837 \%$ & $23,010 \%$ \\
\hline Alumínio & $2,504 \%$ & $3,082 \%$ & $2,456 \%$ & $2,382 \%$ & $2,409 \%$ & $2,214 \%$ & $1,916 \%$ \\
\hline Potássio & $2,282 \%$ & $2,206 \%$ & $2,219 \%$ & $2,193 \%$ & $2,167 \%$ & $2,194 \%$ & $2,193 \%$ \\
\hline Ferro & $0,641 \%$ & $0,620 \%$ & $0,618 \%$ & $9,627 \%$ & $0,620 \%$ & $0,622 \%$ & $0,630 \%$ \\
\hline Enxofre & $0,359 \%$ & $0,351 \%$ & $0,323 \%$ & $0,335 \%$ & $0,336 \%$ & $0,299 \%$ & $0,286 \%$ \\
\hline Estrôncio & $0,034 \%$ & $0,028 \%$ & $0,028 \%$ & $N D^{*}$ & $0,030 \%$ & $0,032 \%$ & $0,029 \%$ \\
\hline
\end{tabular}

${ }^{\star} N D$ - Não detectado 


\subsection{Molhabilidade}

Na Figura 4 são apresentados os resultados dos ensaios de molhabilidade dos filmes antirreflexivos. Os resultados de molhabilidade mostraram que, para todos os filmes, os valores de ângulo de contato foram inferiores a $90^{\circ}$, havendo, portanto 0 molhamento do filme pela água, caracterizando-os como hidrofílicos. A hidrofilicidade do filme de sílica já era esperada, pois sua superfície é constituída de grupos silanóis vicinais $(\mathrm{Si}-\mathrm{OH})$ e geminais $(\mathrm{HO}-\mathrm{Si}-\mathrm{OH})$. Estes grupos silanóis tornam a superfície do filme polar e reativa, permitindo sua interação com moléculas de água fisicamente adsorvidas ou ligadas por ligações hidrogênio ${ }^{1,7-8}$.

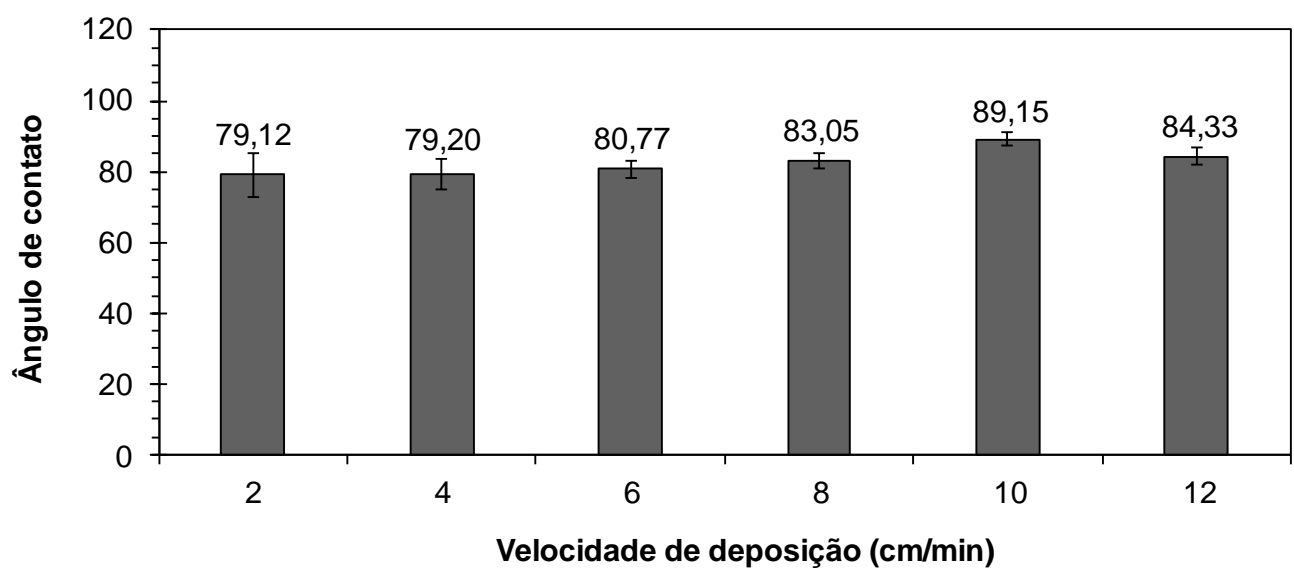

Figura 4. Resultados dos ensaios de molhabilidade dos filmes antirreflexivos.

Na Figura 5 são apresentadas imagens do perfil da gota obtidas durante os ensaios de molhabilidade. A linha tracejada nas imagens representa a superfície do filme antirreflexivo.

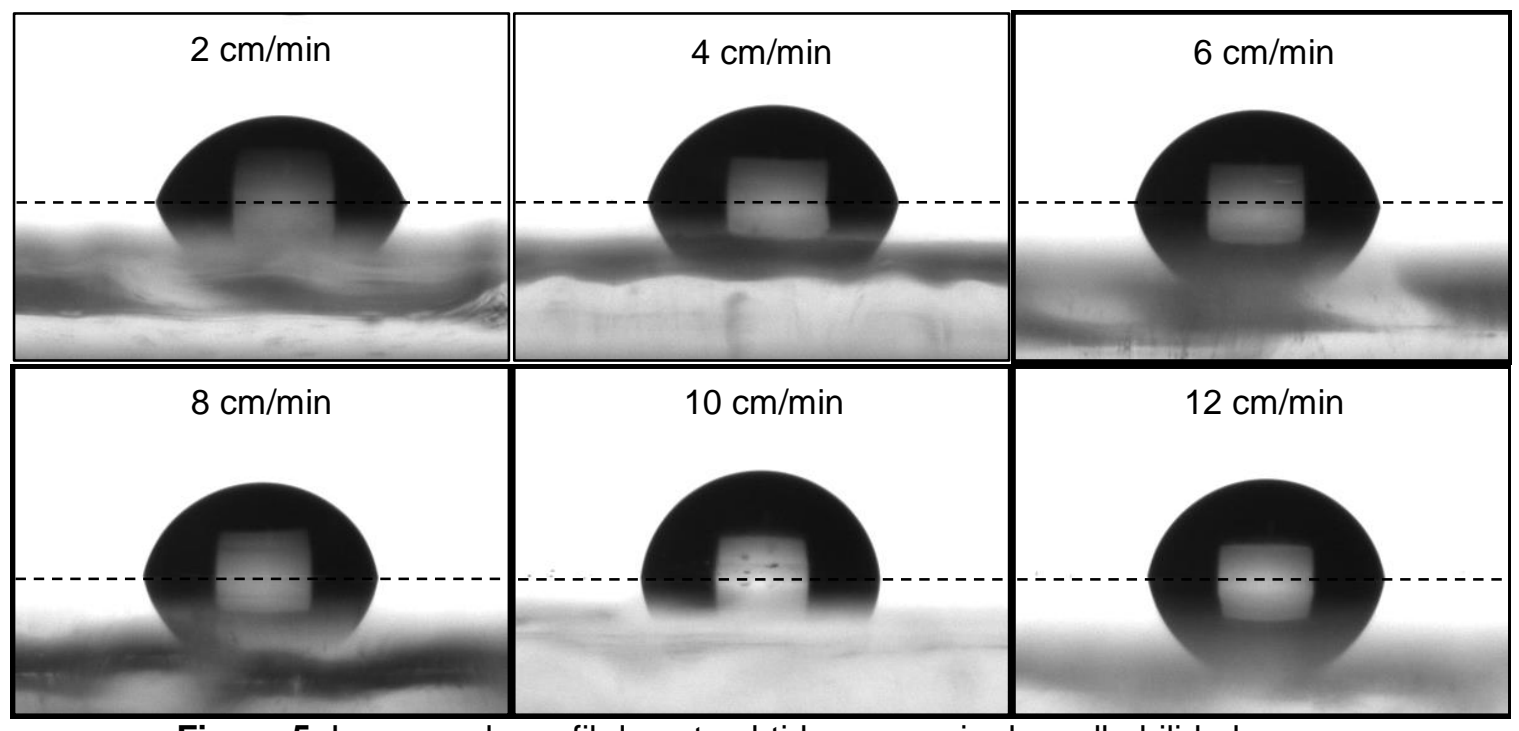

Figura 5. Imagens do perfil da gota obtida no ensaio de molhabilidade. 


\subsection{Adesão e dureza}

A velocidade de deposição dos filmes não afetou a dureza dos mesmos, de forma que todas as amostras apresentaram uma adesão classificada como 4B, demonstrando uma boa força de ligação do filme ao substrato. A dureza dos filmes também se manteve a mesma para todos os filmes, determinada como $3 \mathrm{H}$ e considerada como uma boa resistência ${ }^{3}$.

A Figura 6 apresenta as imagens da amostra com velocidade de $4 \mathrm{~cm} / \mathrm{min}$ após a realização do ensaio de aderência. $\mathrm{Na}$ imagem a são mostrados pontos onde, mesmo após a realização do ensaio, não houve descolamento do filme. Já na imagem B é mostrado um ponto onde houve descolamento do filme. Nota-se que a região onde houve descolamento do filme foi preferencialmente no ponto de interseção dos cortes, caracterizada por uma região fragilizada. A porcentagem total de filme removido foi inferior a $5 \%$.

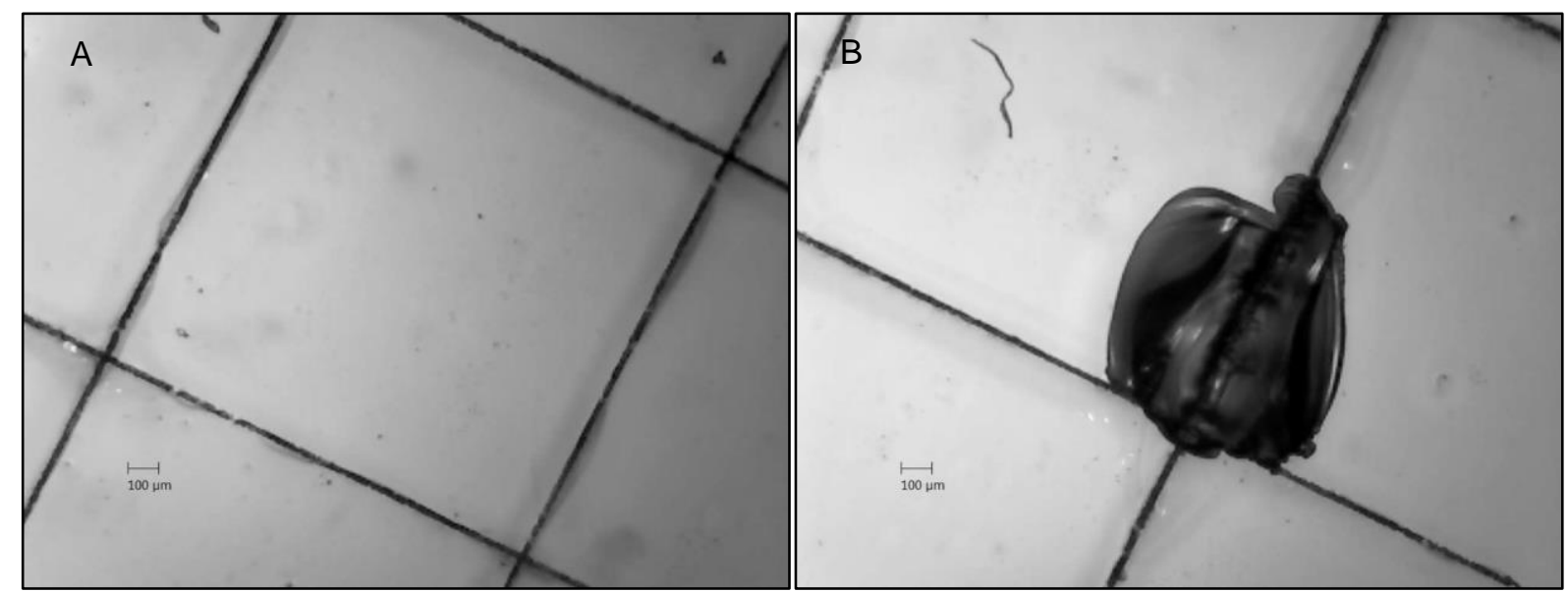

Figura 6: Imagens da amostra com velocidade de deposição de $4 \mathrm{~cm} / \mathrm{mim}$ após a realização do ensaio de adesão com fita, aumento de $10 \mathrm{X}$.

\section{CONCLUSÃo}

Através da metodologia empregada, foram preparados nanofilmes de sílica porosa com ótimas propriedades antirreflexivas. Foi possível reduzir a refletância média, entre os comprimentos de onda de 350 e $900 \mathrm{~nm}$, do substrato $(3,86 \%)$ para um valor mínimo de $2,72 \%$ após o emprego do revestimento antirreflexivo. As análises de microscopia eletrônica de varredura revelaram, dentro do aumento permitido pelo equipamento, que a superfície de todos os filmes se encontra lisa, homogênea e isenta de trincas. Ensaios de fluorescência de raios- $X$ com energia dispersiva comprovaram o aumento da espessura dos filmes com o aumento da velocidade. Ensaios de adesão e dureza revelaram que os filmes apresentaram boas propriedades mecânicas, com uma adesão de 4B e dureza de $3 \mathrm{H}$, permitindo a aplicação do revestimento vítreo em tubos absorvedores de usinas heliotérmicas.

\section{Agradecimentos}

Os autores agradecem ao suporte financeiro fornecido pela CAPES (Coordenação de Aperfeiçoamento de Pessoal de Nível Superior) e à equipe do Laboratório de Físico-química do Departamento de Química da UFMG. 


\section{REFERÊNCIAS}

1 Kesmez, Ö., Çamurlu, H. E., Burunkaya, E., Arpaç, E. Preparation of antireflective $\mathrm{SiO}_{2}$ nanometric films, Ceramics International. 2010, 36:391-394.

2 Kesmez, Ö., Burunkaya, E., Kiraz, N., Çamurlu, H. E., Asiltür, M., Arpaç, E. Effect of acid, water and alcohol ratios on sol-gel preparation of antireflective amorphous $\mathrm{SiO}_{2}$ coatings. Journal of Non-Crystalline Solids. 2011, 357:3130-3135.

3 Xin, C.; Peng, C.; Xu, Y.; Wu, J. A novel route to prepare weather resistant, durable antireflective films for solar glass. Solar Energy. 2013, 93:121-126.

4 Ye, H., Zhang, X., Zhang, Y., Ye, L., Xiao, B. LV, H., Jiang, B. Preparation of antireflective coatings with high transmittance and enhanced abrasion-resistance by a base/acid two-step catalyzed sol-gel process. Solar Energy Materials \& Solar Cells. 2011, 95:2347-2351.

5 San Vicente, G., Bayón, R., Germán, N., Morales, A. Surface modification of porous antireflective coatings for solar glass covers. Solar Energy. 2011, 85:676-680.

6 Brinker, C. J., Scherer, G. W. Sol-Gel science: The physics and chemestry of sol-gel processing. San Diego: Academic Press; 1990.

7 Airoldi, C., Farias, R. F. Alcóxidos como precursores na síntese de novos materiais através do processo sol-gel. Química Nova. 2004, 27(1):84-88.

8 Nassar, E. J., Messaddeq, Y., Ribeiro, S. J. L. Influência da catálise ácida e básica na preparação da sílica funcionalizada pelo método sol-gel. Química Nova. 2002, 25(1):27-31.

9 Karasiński, P. Influence of aging and annealing on the properties of silica films produced with sol-gel method. Optica Applicata. 2006, 36(2-3):389-399.

10 Bautista, M.C., Morales, A. Silica antireflective films on glass produced by the sol-gel method. Solar Energy Materials \& Solar Cells. 2003, 80:217-225.

11 American Society for Testing and Materials. ASTM G173-03, Standard Tables for Reference Solar Spectral Irradiances: Direct Normal and Hemispherical on $37^{\circ}$ Tilted Surface, Estados Unidos, 2012.

12 Ly, M. Desenvolvimento e análise de filme anti-reflexo de sulfeto de zinco para células solares. Dissertação (Mestrado em Engenharia e Tecnologia de Materiais) - Pontifícia Universidade Católica do Rio Grande do Sul, Porto Alegre, Rio Grande do Sul. 2007.

13 ISEP - Instituto Superior de Engenharia do Porto. Laboratórios de Física: Equações de Fresnel. 2008. [acesso em 05 jan. 2016]. Disponível em:

https://www.dfi.isep.ipp.pt/uploads/ficheiros/4022.pdf

14 Karasiński, P., Jaglarz, J., Reben, M., Skoczek, E., Mazur, J. Porous silica xerogel films as antireflective coatings - Fabrication and characterization. Optical Materials. 2011, 33:1989-1994.

15 American Society for Testing and Materials. ASTM D7334-08: Standard Practice for Surface Wettability of Coatings, Substrates and Pigments by Advancing Contact Angle Measurement. Estados Unidos, 2013.

16 American Society for Testing and Materials. ASTM D3359-09: Standard Test Methods for Measuring Adhesion by Tape Test. Estados Unidos, 2010.

17 American Society for Testing and Materials. ASTM D3363-05: Standard Test Method for Film Hardness by Pencil Test. Estados Unidos, 2011.

18 Nardy, A. J. R., Machado, F. B. Mineralogia Óptica - Óptica Cristalina. Rio Claro, São Paulo. Instituto de Geociências e Ciências Exatas, Universidade Estadual Paulista (UNESP). 2002.

19 Chang, K. C., Chen, Y. K., Chen, H. Fabrication of highly transparent and superhydrophobic silica-based surface by TEOS/PPG hybrid with adjustment of the $\mathrm{pH}$ value. Surface \& Coatings Technology. 2008, 202: 3822-3831.

$20 \mathrm{Xu}, \mathrm{Y}$. , Cheng, P., Xin, C., Wu, J. Preparation of silica antireflective films for solar energy application. Materials Letters. 2013, 94: 89-91. 